\title{
Sulfur-containing Alkylidenemalonic Acids Obtained from the Reaction of Thiols with Various Diethyl Acylmalonates
}

\author{
STIG ALLENMARK and OVE BOHMAN \\ Chemical Institute, University of Uppsala, Uppsala, Sweden
}

\begin{abstract}
The reaction of ethanethiol and phenylmethanethiol, respectively, with some diethyl acylmalonates as a method for the preparation of certain alkylthio-substituted, unsaturated malonic acids has been examined. It was found that the nature of the acyl group had a great influence upon the reaction. Thus, from diethyl isobutyrylmalonate $\beta, \gamma$-unsaturated malonic acid derivatives were obtained, whereas diethyl acylmalonates without branching in the acyl group yielded the $\alpha, \beta$-unsaturated compounds. Diethyl pivaloylmalonate as well as diethyl diphenylacetylmalonate failed to react.

In pyridine the $\alpha, \beta$-unsaturated acids rearranged to the $\beta, \gamma-$ isomers which underwent decarboxylation. The same reaction occurred more readily with use of 1,4-diazabicyclo[2.2.2]octane in acetone-water mixtures.

The sulfoxides and sulfones corresponding to the sulfide-acids were also prepared. The sulfoxides of the $\beta, \gamma$-unsaturated compounds were found to decarboxylate in acetone solution much more readily than the corresponding sulfides and sulfones.
\end{abstract}

Tn a previous paper we described the synthesis of alkylthio-substituted alkylidene malonic acids via thiol addition to diethyl acetylmalonate and diethyl propionylmalonate, respectively, and their oxidation products. ${ }^{1}$ A kinetic study of the sulfoxides (VI in Scheme 1) with respect to the reduction of the sulfoxide group in aqueous hydriodic acid showed this reaction to be effectively assisted by intramolecular carboxylic group participation.2 In order to gain more information about the influence of bulky substituents $(R$ and $R^{\prime}$ ) upon the rate of this reaction, some further compounds of this type were needed. For this reason and also in order to investigate the versatility of the method for the preparation of this type of compound, the synthetic work was extended with respect to the carbonyl component in the reaction. We have therefore now studied the thiol addition to some other diethyl acylmalonates and also prepared the oxidation products of the malonic acid derivatives which are formed after hydrolysis.

The synthetic route is shown in the following scheme: 


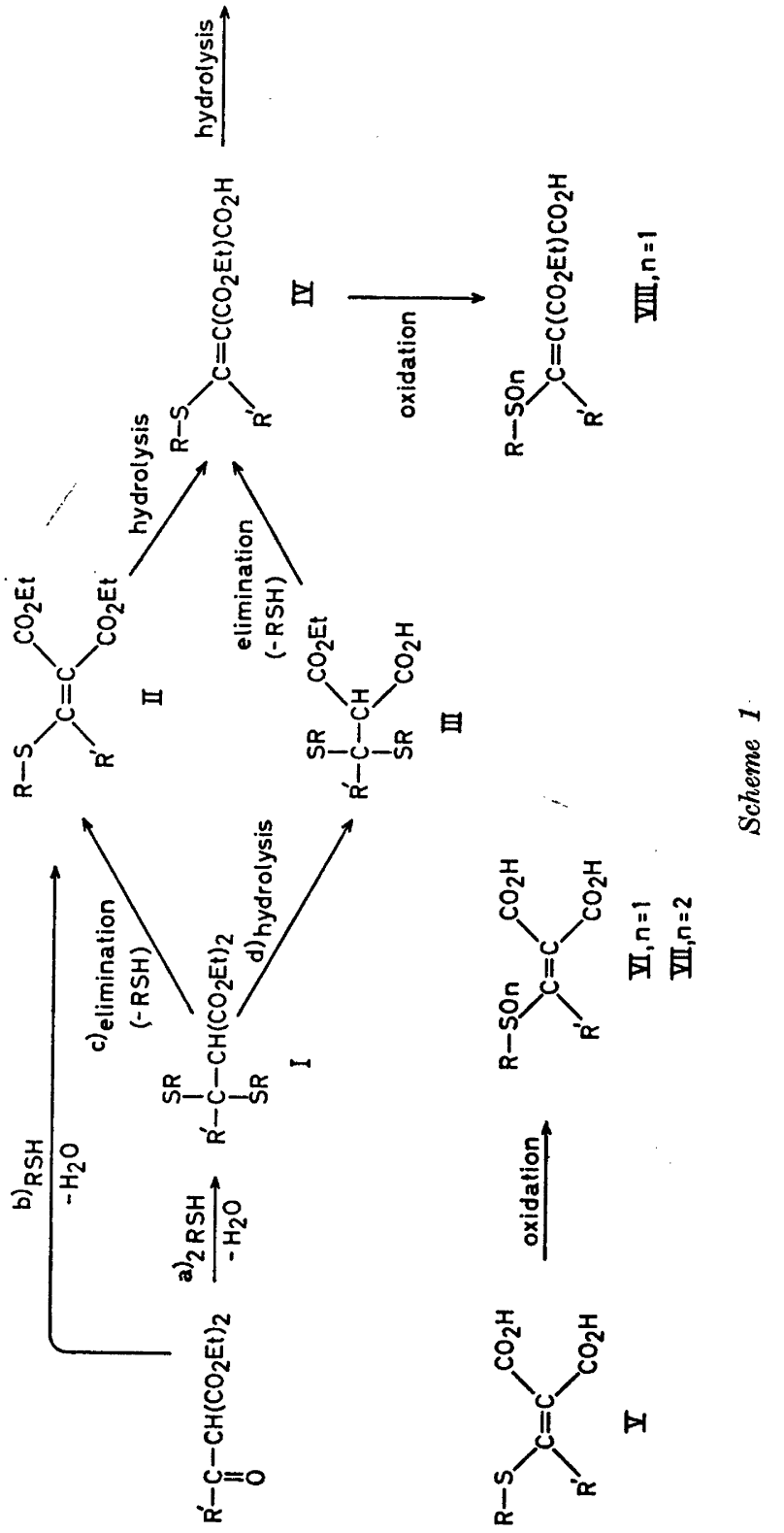

Compounds of type $\mathrm{V}$ could be prepared according to this scheme in varying over-all yields (between 25 and $40 \%)$ when the thiol $\left(\mathrm{R}=\mathrm{C}_{2} \mathrm{H}_{5}\right.$ - or $\mathrm{C}_{6} \mathrm{H}_{5} \mathrm{CH}_{2}-$ ) was reacted in the presence of hydrogen chloride and zinc chloride Acta Chem. Scand. 22 (1968) No. 5 
with diethyl acylmalonates where $\mathrm{R}^{\prime}=\mathrm{CH}_{3}, 1, \mathrm{C}_{2} \mathrm{H}_{5}-1, \mathrm{C}_{6} \mathrm{H}_{5}$, and $\mathrm{C}_{6} \mathrm{H}_{5} \mathrm{CH}_{2}-$. The diethyl phenylacetylmalonate reacted with phenylmethanethiol but not with ethanethiol. Attempts to react diethyl pivaloylmalonate $\left(\mathrm{R}^{\prime}=\left(\mathrm{CH}_{3}\right)_{3} \mathrm{C}-\right)$ and diethyl diphenylacetylmalonate $\left(\mathrm{R}^{\prime}=\left(\mathrm{C}_{6} \mathrm{H}_{5}\right)_{2} \mathrm{CH}-\right)$ with ethanethiol as well as phenylmethanethiol failed, a result in agreement with the findings of Campaigne and Leal, ${ }^{3}$ who found that pivalophenone did not react with thiophenol for steric reasons.

With diethyl isobutyrylmalonate $\left(\mathrm{R}^{\prime}=\left(\mathrm{CH}_{3}\right)_{2} \mathrm{CH}-\right)$ the reaction took another course, yielding $\beta, \gamma$-unsaturated compounds, as ascertained from product analyses. The various kinds of compounds that could be prepared in this case are shown in Scheme 2.

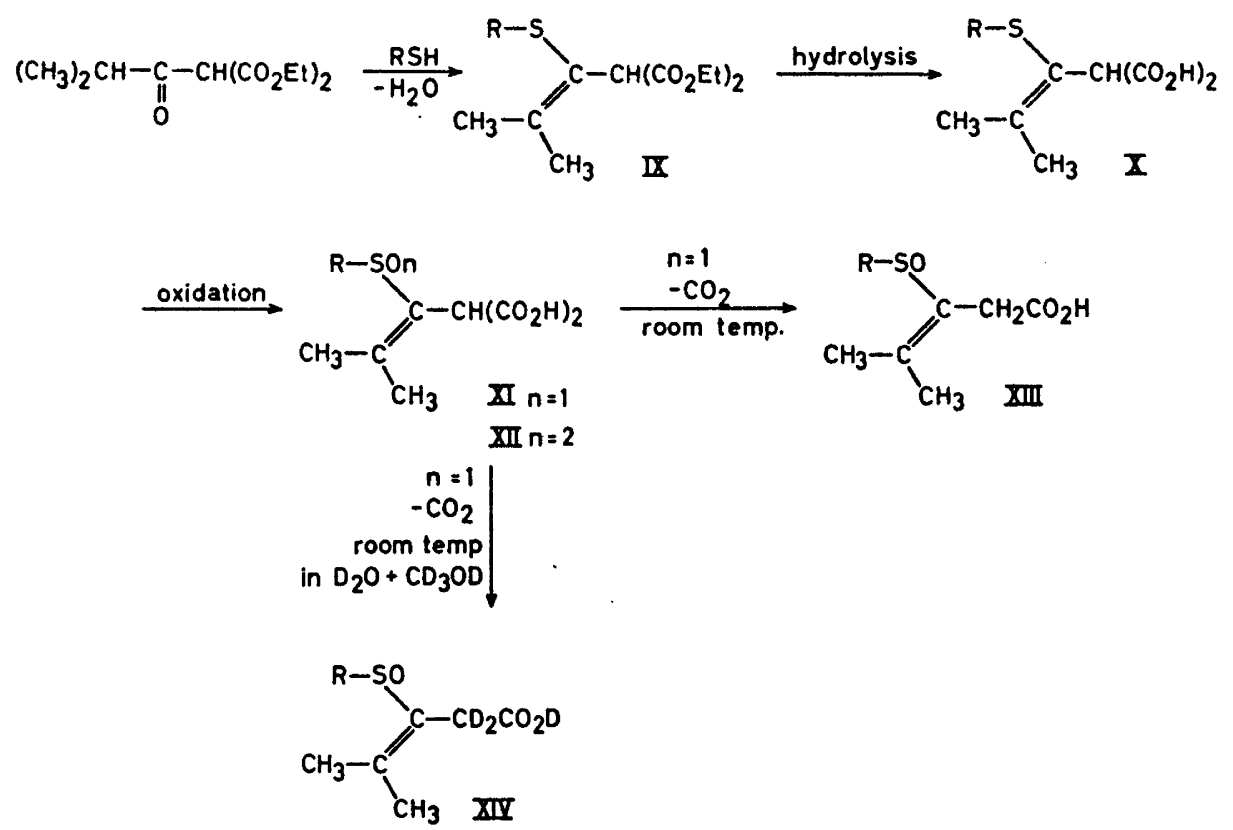

Scheme 2.

As illustrated in Scheme 1, the reaction between the diethyl acylmalonate and two moles of the thiol leads to a dithioketal-diester (I, route $a$ ). This was found for $\mathrm{R}^{\prime}=\mathrm{CH}_{3}-$ and $\mathrm{C}_{2} \mathrm{H}_{5}-$. For $\mathrm{R}^{\prime}=\mathrm{C}_{6} \mathrm{H}_{5} \mathrm{CH}_{2}-$ the identification of the initially formed product after the first step met with difficulties, so whether the reaction passes mostly via $\mathrm{I}$ in route $a$ or by the direct route $b$ is uncertain. For $\mathrm{R}^{\prime}=\mathrm{C}_{6} \mathrm{H}_{5}$ - the reaction was found to give only an unsaturated diester (II) according to $b$. This is not unexpected as in this case the primarily formed hemithioketal is more stabilized by water elimination to form II, than by reaction with another molecule of thiol, because here, 
conjugation with the phenyl group in the unsaturated compound becomes a rather important factor among those influencing the course of the reaction.

The further reaction of I could occur along two routes, $(c$ and $d)$, both finally yielding an unsaturated half-ester (IV). With a base like potassium hydroxide in absolute ethanol, elimination of thiol occurred with the formation of II, which then could be partially hydrolyzed to yield IV. When this reaction was carried out in $80 \%$ ethanol, i.e. under conditions where also hydrolysis of the first ester group is possible, II and the dithioketal-half-ester (III) were both formed, which means that $c$ and $d$ are concurrent reaction paths under these conditions. Dithioketals of acetoacetic acid have been prepared by Hauptmann and Giora by hydrolysis of the corresponding esters under very mild conditions. They also showed that these compounds could very readily eliminate thiol, thus yielding 3-alkylthio-cis-crotonic acids.

Compound IV, which consisted of a mixture of geometric isomers, was readily hydrolyzed to the unsaturated malonic acid $(\mathbb{})$, which in turn upon oxidation with peracetic acid in ether or acetone gave the corresponding sulfoxide (VI) and sulfone (VII) in good yield. As reported earlier, ${ }^{1}$ the conversion of $I$ to $\mathrm{V}$ can be performed in one reaction without isolation of any of the intermediate products II, III, or IV, if a sufficient amount of alkali hydroxide in a water-ethanol mixture is used.

The sulfoxide VIII could be prepared by oxidation of IV with an equivalent amount of peracetic acid.

A $\beta, \gamma$-unsaturated diester (IX, Scheme 2) was the only observed product from the reaction of thiol with diethyl isobutyrylmalonate. By alkaline hydrolysis of IX the $\beta, \gamma$-unsaturated malonic acid (X) was formed, which was oxidized to the sulfoxide (XI) and sulfone (XII). Compound XI was found to decarboxylate extremely readily, the rate of the reaction being measurable at room temperature in acetone solution. Thus, upon two recrystallizations of XI from ethyl acetate (b.p. $77^{\circ}$ ) the mono-acid (XIII) was obtained almost quantitatively. If the decarboxylation of XI was allowed to take place in a mixture of methanol- $d_{4}$ and deuterium oxide, the resulting product (XIV) was completely $\alpha$-deuterated.

A similarly facile decarboxylation reaction was not found for X or XII. These compounds could therefore be recrystallized without difficulty, although in acetone at $60^{\circ}$ a very slow decarboxylation was observable by NMR-studies. A preliminary investigation has given, as a result, that the rate of decarboxylation in acetone decreases in the following order: $\mathrm{XI}>\mathrm{XII}>\mathrm{X}$.

The results indicate an interaction between the sulfoxide and carboxyl functions in the decarboxylation of XI. It is probable that the sulfoxide group, being the most basic one and forming the strongest hydrogen bonds of the three sulfur-functions in the series, ${ }^{5,6}$ will assist the formation of the carboxylate anion (necessary for direct decarboxylation of the acid ${ }^{7}$ ) through an intramolecular process. In the case of $\mathrm{X}$ the reaction is likely to follow the mechanism proposed for decarboxylation of ordinary malonic acids. ${ }^{7-9}$

The formation of the dithioketals and unsaturated sulfides, respectively, from the reaction between thiophenol and certain ketones has been studied earlier by Campaigne and Leal ${ }^{3}$ who also discussed the mechanism of the reactions. Our results concerning the reaction between thiol and the diethyl 
acylmalonate are fully consistent with their proposed mechanism. Thus, protonation of the primarily formed hemithioketal and loss of a water-molecule yields a carbonium ion, the further reaction of which can proceed according to two routes: $a$ ) reaction with a second molecule of thiol yielding a dithioketal or $b$ ) loss of a proton with the formation of an unsaturated sulfide. Whether $a$ or $b$ occurs should be dependent upon both steric and electronic factors.

Firstly, if the steric screening of the carbonium carbon is great, $b$ should be favoured relative to $a$, secondly, electron-releasing substituents $\mathrm{R}^{\prime}$ should favour the electron-shift leading to $b$, whereas electron-withdrawing substi-

Table 1. Products formed from the reaction between diethyl acylmalonates and thiols.

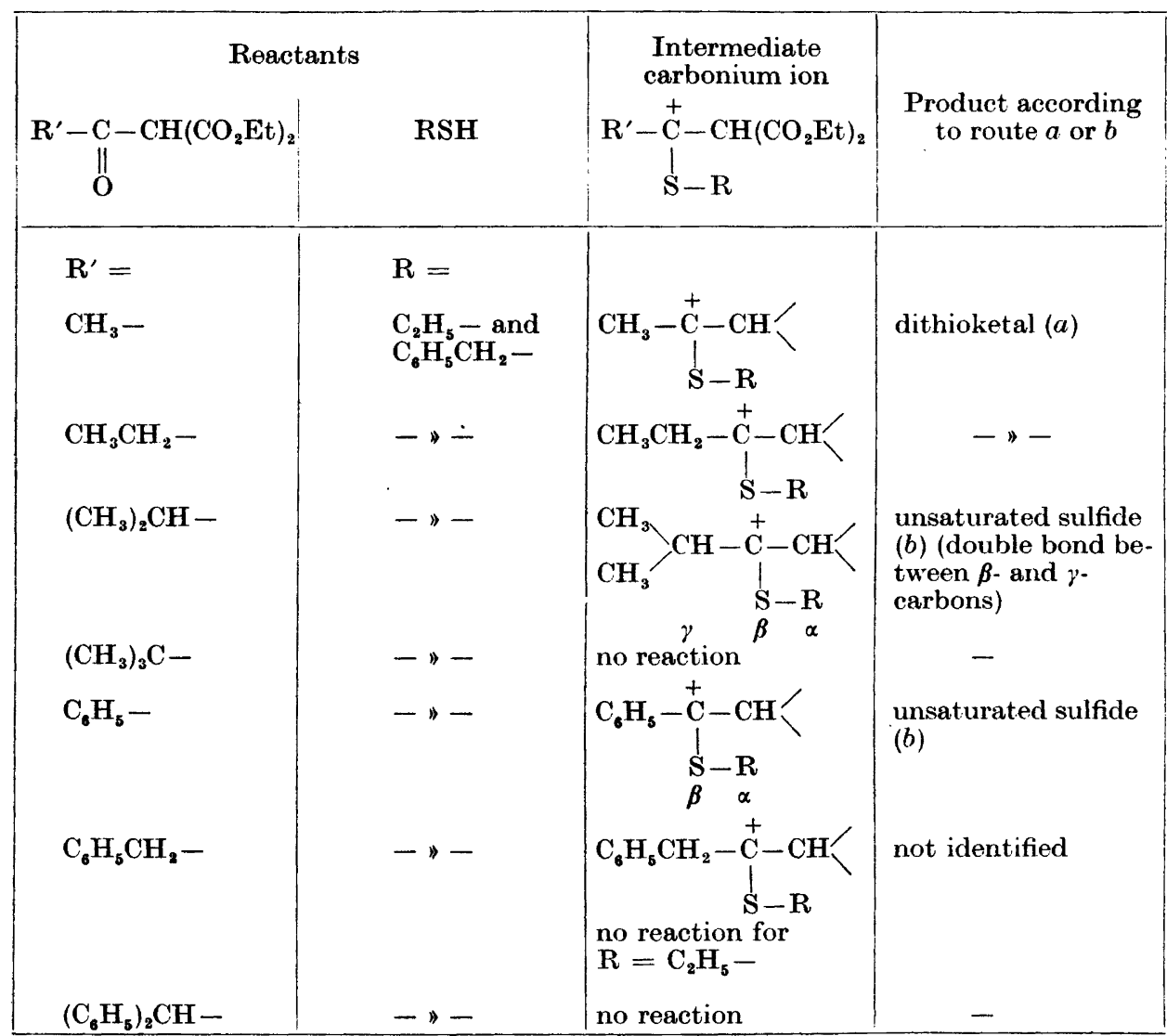

tuents should not. Our results are summarized in Table 1. As expected according to the previous discussion, an increased number of methyl groups in $\mathbf{R}^{\prime}$ will change the reaction from route $a$ to route $b$ and finally to no reaction at all for the most substituted $R^{\prime}$. For $R^{\prime}=C_{6} H_{5}$, we obtained the unsaturated 

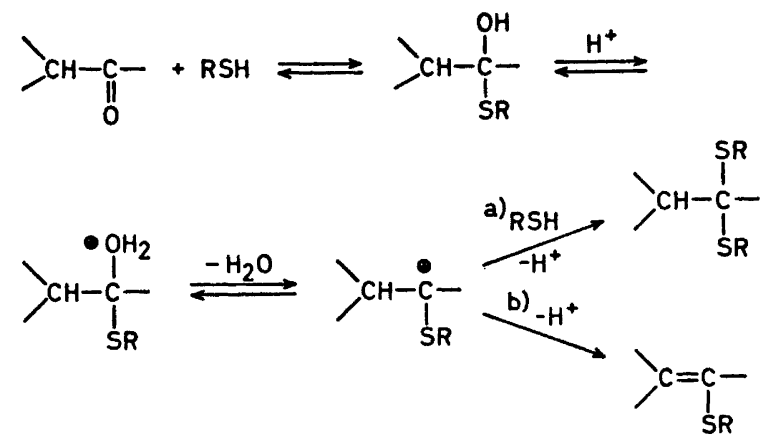

Scheme 3.

sulfide, whereas Campaigne and Leal ${ }^{3}$ found that ethyl benzoylacetate gave a dithioketal with thiophenol. This difference is most likely due to the much greater steric hindrance to nucleophilic attack at the carbonium carbon in the intermediate in our case.

\section{STRUCTURE DETERMINATION FROM NMR-SPECTRA}

The structures of IX-XIV were definitely established by NMR; all spectra showing the pattern of chemical shift difference, due to magnetic nonequivalence between the two geminal methyl groups. This is consistent with an isopropylidene structure where the spacing between the peaks corresponding to the two types of methyl protons is mainly dependent upon anisotropy effects influencing one methyl group more than the other. In the case of an isopropyl structure, the two peaks would have been the result of coupling with the vicinal proton and thus have shown an almost constant spacing of around 7 cps corresponding to the coupling constant.

Making the reasonable assumption that the methyl protons located cis to the sulfur atom in X-XII are shifted more than the trans-methyl protons on passing from sulfide to sulfoxide, it can be deduced from Table 2 that a sulfoxide group causes a diamagnetic shift of the cis-methyl protons, in comparison with a sulfide or even a sulfone group, which cannot be accounted for in terms of inductive effects. The inductive effects on the chemical shifts of the ethylenic protons in cis- and trans-3-arylthio-, 3-arylsulfinyl-, and 3arylsulfonylacrylic acids have been discussed by Hogeveen et al. ${ }^{10}$ The observed behaviour is also consistent with earlier results. Thus, NMR-spectra of 3alkylthio-2-methyl-cis-crotonic acid (3-alkylthioangelic acid) and the corresponding sulfoxide have shown that the replacement of the divalent group by a sulfoxide function is accompanied by a diamagnetic shift of the protons of the cis-methyl group."

Rather few investigations on the anisotropy of the sulfoxide group seem to have been made; most work in this respect appears to have been performed on ring systems..$^{12-17}$ In the reported cases, the anisotropy of the sulfoxide group

Acta Chem. Scand. 22 (1968) No. 5 


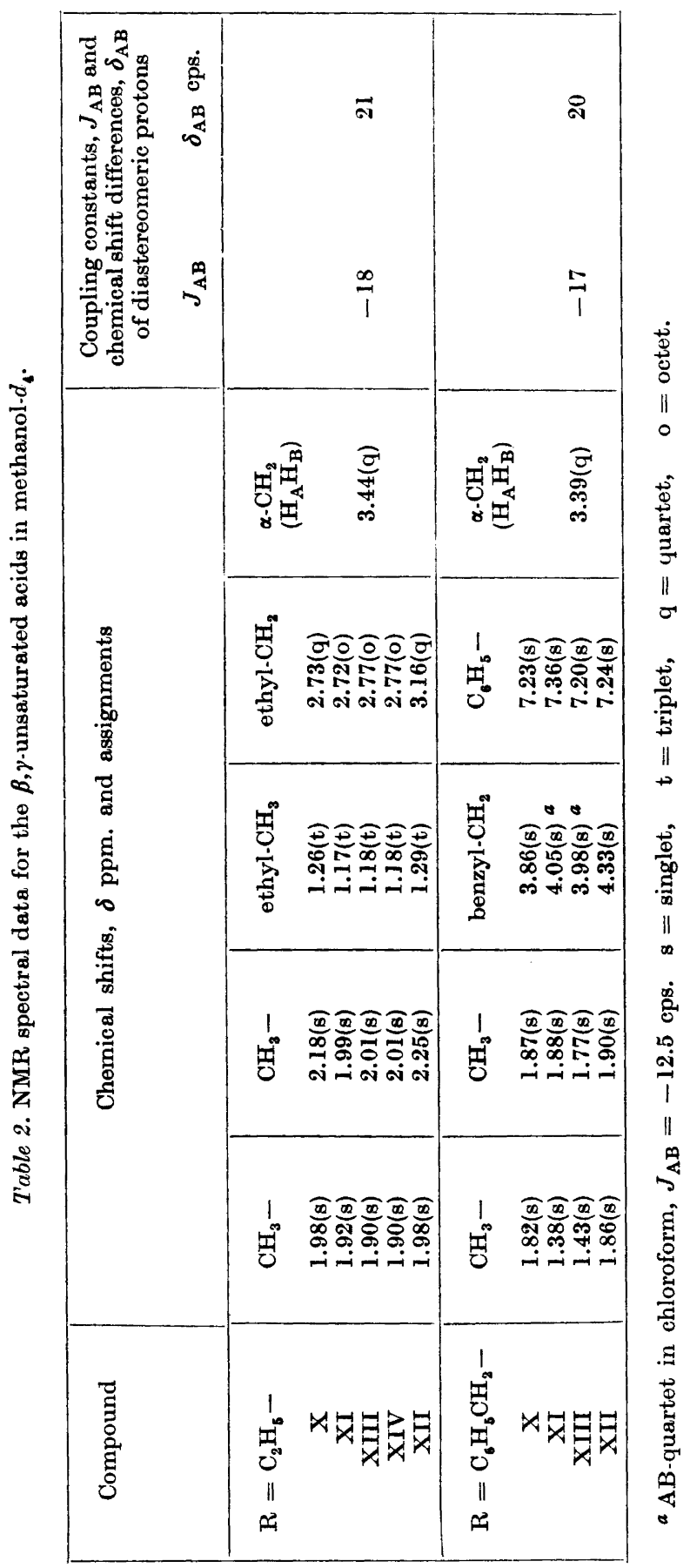

Acta Chem. Scand. 22 (1968) No. 5 
causes a paramagnetic shift for protons in a syn-axial position, i.e. the proton in question will be situated very near an axis perpendicular to the $\mathrm{S}-\mathrm{O}$ bond and passing through the centre of the latter. The data reported by Foster et al.17 further show, however, that protons lying near the sulfur atom and almost in line with the direction of the $\mathrm{S}-\mathrm{O}$ bond will undergo considerable diamagnetic shielding resulting in a shift towards higher field in comparison with the corresponding sulfides and sulfones. This behaviour is in agreement with a diamagnetic anisotropy effect of acetylenic type for the sulfoxide bond. ${ }^{15,17}$ Thus, in our opinion, the assignment of sulfoxide configuration by the NMR-method is better based upon the observation of the rather great diamagnetic (i.e. upfield) shifts for protons lying near the sulfur atom and in line with the $\mathrm{S}-\mathrm{O}$ bond.

Our investigated system is more flexible and not directly comparable with the cyclic ones without a knowledge of the arrangement of the various groups in the most stable conformation. A more precise interpretation of the diamagnetic shift in this case must therefore wait until further data are available.

Fig. 1 shows the NMR-spectra of compounds $\mathrm{X}-\mathrm{XIII}\left(\mathrm{R}=\mathrm{C}_{6} \mathrm{H}_{5} \mathrm{CH}_{2}-\right)$. It is evident that the AB-quartet in XIII is due to the two diastereomeric protons at the $\alpha$-carbon in this acid because it disappeared in XIV, which was shown for $\mathrm{R}=\mathrm{C}_{2} \mathrm{H}_{5}$ - (Table 2). The likewise diastereomeric methylene protons in the benzyl group appear as an $\mathrm{A}_{2}$-singlet at a rather constant position around $\delta=4.0 \mathrm{ppm}$ in XI as well as in XIII. In chloroform, however, these benzyl protons form an AB-quartet. Such a magnetic non-equivalence of diastereomeric protons in benzyl methyl sulfoxide has earlier also been shown by NMR-methods to be associated with a kinetic non-equivalence upon hydrogen exchange.18,19 The great variation of the chemical shift difference between diastereomeric protons with the solvent $\left(\mathrm{AB}-\mathrm{A}_{2}\right)$ has also been pointed out previously. ${ }^{20,21}$

The absolute value of the coupling constant was found to be greater for the $\alpha$-protons than for the methylene protons in the benzyl group by 5 cps (Table 2). The value of the latter is in good agreement with the value found for benzyl methyl sulfoxide, ${ }^{18}\left|J_{\mathrm{AB}}\right|=13.0 \mathrm{cps}$.

\section{BASE-CATALYZED REARRANGEMENTS WITH SUBSEQUENT DECAR- BOXYLATIONS}

Because of the great difference between sulfoxides VI and XI with respect to their tendency for decarboxylation, we also undertook a preliminary study of the decarboxylation of the sulfides $\mathrm{V}$ and $\mathrm{X}$ in pyridine at $50^{\circ}$. The reaction mixtures were conveniently studied directly with the use of NMR-technique. We found that the $\beta, \gamma$-unsaturated malonic acids $\mathrm{X}$ were completely converted to the corresponding mono-acids after $3 \mathrm{~h}$ under these conditions. The $\alpha, \beta$ unsaturated acids $\mathrm{V}$ reacted more slowly, being first converted to the corresponding $\beta, \gamma$-isomers which then decarboxylated. Thus, $\mathrm{V}\left(\mathrm{R}=\mathrm{C}_{6} \mathrm{H}_{5} \mathrm{CH}_{2}-\right.$, $\mathrm{R}^{\prime}=\mathrm{C}_{2} \mathrm{H}_{5}-$ ) was completely converted to the $\beta, \gamma$-unsaturated mono-acid after $24 \mathrm{~h}$ at $70^{\circ}$, but $3 \mathrm{~h}$ at $50^{\circ}$ gave less than $40 \%$. The reaction, which is quite consistent with the results of Corey ${ }^{22-24}$ for the decarboxylation of

Acta Chem. Scand. 22 (1968) No. 5 

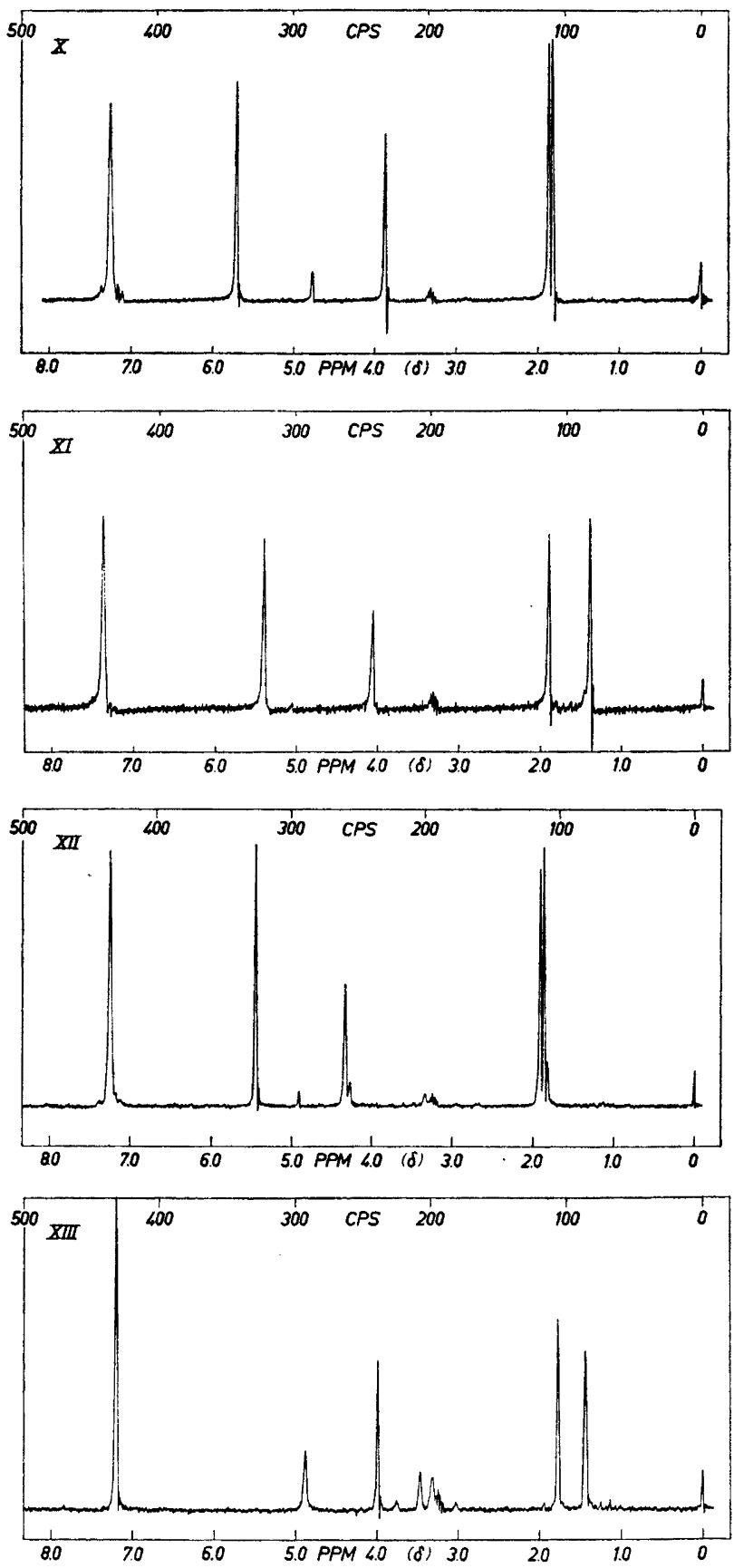

Fig. 1. NMR-spectra of $\mathrm{X}-\mathrm{XIII}\left(\mathrm{R}=\mathrm{C}_{6} \mathrm{H}_{6} \mathrm{CH}_{2}-\right)$ in methanol-d.

Acta Chem. Scand. 22 (1968) No. 5 
$\alpha, \beta$ - and $\beta, \gamma$-unsaturated malonic acids in boiling pyridine $\left(111^{\circ}\right)$, may be pictured according to Scheme 4.

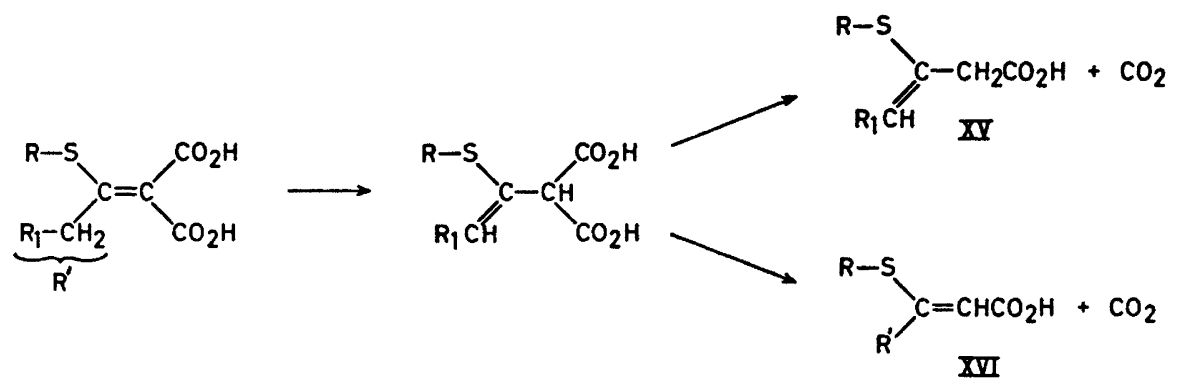

Scheme 4.

The decarboxylation of $\mathrm{V}\left(\mathrm{R}=\mathrm{C}_{6} \mathrm{H}_{5} \mathrm{CH}_{2}-, \mathrm{R}^{\prime}=\mathrm{CH}_{3}-\right)$ yielded a mixture of XV and XVI.

By using 1,4-diazabicyclo[2.2.2]octane (DABCO), the reaction described in Scheme 4 was accelerated and could be performed in acetone-water mixtures at room temperature. Making use of this method, we were able to isolate the $\beta, \gamma$-mono-acid XV $\left(\mathrm{R}=\mathrm{C}_{6} \mathrm{H}_{5} \mathrm{CH}_{2}-, \mathrm{R}_{1}=\mathrm{CH}_{3}-\right)$ m.p. $45-47^{\circ}$ by careful acidification and extraction with ether.

The sulfoxides XI decarboxylated very readily under these conditions too. Thus, in a typical experiment $\mathrm{XI}\left(\mathrm{R}=\mathrm{C}_{2} \mathrm{H}_{5}-\right)$ was completely converted to XIII after $45 \mathrm{~min}$ at $50^{\circ}$.

The other compounds have not yet been investigated with respect to this reaction. Work on this subject is, however, in progress in this laboratory.

\section{EXPERIMENTAL}

\section{Preparation of diethyl acylmalonates}

The procedure described by Lund ${ }^{25}$ was used, i.e. diethyl malonate, magnesium, and absolute ethanol were first allowed to react and when the evolution of hydrogen had ceased the mass was dissolved by the addition of ether. The acyl chloride, diluted with some ether, was added slowly. Then the mixture was refluxed for a short time and after cooling, acidified with dilute sulfuric acid. The ether phase which then separated was washed with water and dried. After evaporation of the ether, the residue was vacuumdistilled. In one case, however, vacuum-distillation could not be performed, but instead the substance which solidified on standing, was purified by recrystallization. The compounds given below were prepared.

Diethyl acetylmalonate was obtained in $81 \%$ yield. B.p. $109^{\circ} / 10 \mathrm{~mm}, n_{\mathrm{D}}{ }^{22}=1.4480$. (Ref. 26: B.p. $115-117^{\circ} / 13 \mathrm{~mm}, n_{\mathrm{D}}{ }^{20}=1.4477$ ).

Diethyl propionylmalonate was obtained in $75 \%$ yield. B.p. $124^{\circ} / 8 \mathrm{~mm}, n_{\mathrm{D}}{ }^{21}=1.4448$. (Ref. 27: B.p. $137^{\circ} / 14 \mathrm{~mm}, n_{\mathrm{D}}{ }^{20}=1.4420$ ).

Diettyl benzoylmalonate. The reaction of benzoyl chloride with the magnesium com. pound of diethyl malonate gave $79 \%$ of this ester with b.p. $152^{\circ} / 0.2 \mathrm{~mm}, n_{\mathrm{D}}{ }^{24}=1.5071$. (Ref. 28: B.p. $169-170^{\circ} / 5 \mathrm{~mm}, n_{\mathrm{D}}{ }^{20}=1.5103$ ).

Diethyl phenylacetylmalonate. Similarly, the reaction of phenylacetyl chloride with the magnesium compound of diethyl malonate yielded $75 \%$ of this ester. B.p. $165-$

Acta Chem. Scand. 22 (1968) No. 5 
$166^{\circ} / 0.15 \mathrm{~mm}, n_{\mathrm{D}}{ }^{20.5}=1.5050$. (Ref. 29: B.p. $120^{\circ} / 0.01 \mathrm{~mm}$ ). (Found: C 64.83; H 6.47. Calc. for $\mathrm{C}_{15} \mathrm{H}_{18} \mathrm{O}_{5}$ : C 64.74; $\left.\mathrm{H} 6.52\right)$.

Diethyl pivaloylmalonate. From $126.5 \mathrm{~g}$ (1.05 mole) of pivaloyl chloride (prepared from pivalic acid and benzoyl chloride $\left.{ }^{30}\right)$ and $160 \mathrm{~g}$ ( 1.0 mole) of diethyl malonate $211 \mathrm{~g}$ $(87 \%)$ of this compound was obtained. B.p. $134-136^{\circ} / 8 \mathrm{~mm}, n_{\mathrm{D}}{ }^{18}=1.4358$. (Ref. 31: B.p. $139^{\circ} / 10 \mathrm{~mm}$ ). (Found: C 58.99; $\mathrm{H} \mathrm{8.18}$. Calc. for $\mathrm{C}_{12} \mathrm{H}_{20} \mathrm{O}_{5}: \mathrm{C} \mathrm{59.00;} \mathrm{H} \mathrm{8.25}$ ).

Diethyl diphenylacetylmalonate. From $43.5 \mathrm{~g}(0.188 \mathrm{~mole})$ of diphenylacetyl chloride ${ }^{32}$ and $27.8 \mathrm{~g}(0.174$ mole $)$ diethyl malonate $55 \mathrm{~g}(90 \%)$ of this ester was isolated. It solidified to a mass which on recrystallization from ethanol gave a white crystalline product with m.p. 65-67 . Attempts to vacuum-distil this compound were unsuccessful because of a considerable decomposition with the evolution of gas on distillation at $220^{\circ} / 0.2 \mathrm{~mm}$. (Found: C 71.21; $\mathrm{H} \mathrm{6.25}$. Calc. for $\mathrm{C}_{21} \mathrm{H}_{22} \mathrm{O}_{5}$ : C 71.17; $\mathrm{H} 6.26$ ).

Diethyl isobutyrylmalonate was obtained in $76 \%$ yield. B.p. $125-126^{\circ} / 9 \mathrm{~mm}$, $n_{\mathrm{D}}{ }^{23}=1.4442$. (Ref. 33: B.p. $126-127^{\circ} / 10 \mathrm{~mm}, n_{\mathrm{D}}{ }^{15.4}=1.4428$ ).

\section{Preparation of dithioketal-diesters and unsatu- rated diesters}

The method described earlier ${ }^{1}$ was used, i.e. a mixture of the diethyl acylmalonate, the thiol, and zinc chloride was saturated with hydrogen chloride and allowed to stand at room temperature until a separation of the liquid into two phases showed no further change. Then the whole was poured onto ice-water and extracted with chloroform. After drying the solution, the chloroform was evaporated and then the excess thiol and unreacted diethyl acylmalonate was distilled from the residue yielding a crude product consisting of a dithioketal-diester, an unsaturated diester or a mixture of both, depending upon the diethyl aoylmalonate used in the reaction. Thus, from diethyl benzoylmalonate and diethyl isobutyrylmalonate, unsaturated esters were formed directly, while from the other diethyl acylmalonates that did react, dithioketal-diesters were the main products. In the case of diethyl phenylacetylmalonate, however, the structure of the product formed is questionable, because the latter could not be purified by distilling off the starting material still present in considerable amount after the reaction.

In two cases the crude product could be vacuum-distilled and in this way the compounds described below were obtained in a comparatively pure state.

Diethyl 2,2-bis-(ethylthio)-propan-1,1,-dicarboxylate $\left(\mathrm{I}, \mathrm{R}=\mathrm{C}_{2} \mathbf{H}_{5}-, \mathrm{R}^{\prime}=\mathrm{CH}_{3}\right.$ ) was isolated by distillation of the crude product obtained from the reaction between diethyl acetylmalonate and ethanethiol as described earlier. ${ }^{1}$ B.p. $154.5-157^{\circ} / 0.25 \mathrm{~mm}$, $n_{\mathrm{D}}{ }^{22}=1.4908$.

Diethyl 2-ethylthio-3-methyl-2-buten-1,1-dicarboxylate ( $\mathrm{IX}, \mathrm{R}=\mathrm{C}_{2} \mathrm{H}_{5}-$ ) was the only product obtained from the reaction between diethyl isobutyrylmalonate and ethanethiol. It was purified by vacuum-distillation; b.p. $117^{\circ} / 0.15 \mathrm{~mm}, n_{\mathrm{D}}{ }^{20}=1.4815$. (Found: C 56.89; $\mathrm{H} \mathrm{8.07;} \mathrm{S}$ 12.31. Calc. for $\mathrm{C}_{13} \mathrm{H}_{22} \mathrm{O}_{4} \mathrm{~S}$ : C 56.96; $\mathrm{H} 8.08 ; \mathrm{S} 11.69$ ).

In those cases where the initially formed product consisted of a dithioketal-diester, the unsaturated ester was obtained on treatment of the dithioketal-diester with one equivalent of potassium hydroxide in absolute ethanol at room temperature for $12 \mathrm{~h}$, after which time the whole was diluted with water and extracted with ether. Drying of the ether solution and evaporation of the ether yielded a product from which the compounds described below were obtained in a relatively pure state by vacuum-distillation or, when this could not be made, by bringing the compound to crystallization. Recrystallizations were made from ethyl acetate-petroleum ether.

Diethyl 2-ethylthio-1-propen-1,1-dicarboxylate (II, $\mathrm{R}=\mathrm{C}_{2} \mathrm{H}_{5}-, \mathrm{R}^{\prime}=\mathrm{CH}_{3}-$ ). B.p. $140-141^{\circ} / 0.2 \mathrm{~mm}, n_{\mathrm{D}}{ }^{10}=1.5045$. (Found: C 53.17; $\mathrm{H} 7.49 ; \mathrm{S} 14.95$. Calc. for $\mathrm{C}_{11} \mathrm{H}_{18} \mathrm{O}_{4} \mathrm{~S}$ : 53.64; H 7.37; S 13.02).

Diethyl 2-benzylthio-1-propen-1,1-dicarboxylate (II, $\mathrm{R}=\mathrm{C}_{6} \mathrm{H}_{5} \mathrm{CH}_{2}-, \mathrm{R}^{\prime}=\mathrm{CH}_{3}-$ ).

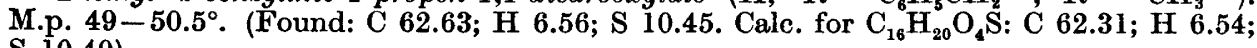
S 10.40).

Diethyl 2-ethylthio-1-buten-1,1-dicarboxylate (II, $\mathrm{R}=\mathrm{C}_{2} \mathrm{H}_{5}-, \quad \mathrm{R}^{\prime}=\mathrm{C}_{2} \mathrm{H}_{5}-$ ). B.p. $122-123^{\circ} / 0.15 \mathrm{~mm}, n_{\mathrm{D}}{ }^{20}=1.5010$. (Found: C 55.13; H 7.77; S 12.29. Calc. for $\mathrm{C}_{12} \mathrm{H}_{20} \mathrm{O}_{4} \mathrm{~S}$ : C 55.36; H 7.74; S 12.32). 


\section{Preparation of dithioketal-half-esters and unstu- rated half-esters}

The unsaturated half-esters described here could be obtained by mixing the crude product described in the previous section with one equivalent of potassium hydroxide in $80 \%$ ethanol and allowing the resulting solution to stand for 2 days at $40^{\circ}$ after which time it was almost neutral. Then the solution was extracted with ether in order to remove any unchanged diester and liberated thiol. Careful acidification and extraction with ether finally yielded the half-ester. In one case where the reaction mixture had been kept at room temperature for 4 days, we were also able to isolate (besides the unsaturated half-ester) a dithioketal-half-ester. The unsaturated half-esters were all obtained as mixtures of cis-trans-isomers; this was easily observed from the NMR-spectra of the products.

Ethyl hydrogen 2-ethylthio-1-propen-1,1-dicarboxylate (IV, $\mathbf{R}=\mathrm{C}_{8} \mathrm{H}_{5}-, \mathrm{R}^{\prime}=\mathrm{CH}_{3}-$ ). M.p. 81-82 ${ }^{\circ}$ (decomp.). (Found: C 49.61; H 6.51; S 14.55; equiv. wt. 220.0. Calc. for $\mathrm{C}_{9} \mathrm{H}_{14} \mathrm{O}$ S: C 49.56; $\mathrm{H}$ 6.47; $\mathrm{S} 14.69$; equiv. wt. 218.3). By repeated recrystallizations from ethyl acetate-petroleum ether one of the isomers could be obtained in a pure state. Its geometric configuration is, however, still questionable.

Ethyl hydrogen 2-benzylthio-1-propen-1,1-dicarboxylate (IV, $\mathrm{R}=\mathrm{C}_{6} \mathrm{H}_{5} \mathrm{CH}_{2}$-, $\mathbf{R}^{\prime}=\mathrm{CH}_{3}-$ ). M.p. 123.5-124 (decomp.). (Found: C 59.83; $\mathrm{H}$ 5.71; S 11.54. Calc. for $\mathrm{C}_{14} \mathrm{H}_{10} \mathrm{O}_{4} \mathrm{~S}$ : C 59.98; H 5.75; S 11.44). Repeated recrystallizations from ethyl acetate gave an almost pure single isomer, the configuration of which so far being undetermined.

Ethyl hydrogen 2,2-bis-(ben:ylthio)-propan-1,1-dicarboxylate (III, $\mathrm{R}=\mathrm{C}_{6} \mathrm{H}_{5} \mathrm{CH}_{2}$-, $\mathbf{R}^{\prime}=\mathbf{C H}_{3}-$ ). This dithioketal-half-ester could be isolated from a mixture with the previous compound. It was recrystallized from ethyl acetate. M.p. 105-106 ${ }^{\circ}$ (decomp.). (Found: C 62.35; H 5.93; $\mathrm{S} 15.72$; equiv. wt. 402.9. Calc. for $\mathrm{C}_{21} \mathrm{H}_{24} \mathrm{O}_{4} \mathrm{~S}_{2}: \mathrm{C} 62.35 ; \mathrm{H} \mathrm{5.98}$; S 15.85; equiv. wt. 404.6).

Ethyl hydrogen 2-ethylthio-2-phenyl-ethen-1,1-dicarboxylate (IV, $\quad \mathrm{R}=\mathrm{C}_{2} \mathrm{H}_{5}$-, $\mathbf{R}^{\prime}=\mathbf{C}_{6} \mathbf{H}_{5}-$ ). A recrystallization from ethyl acetate-petroleum ether gave a product of m.p. 158-159.5 (decomp.). (Found: C 59.93; H 5.77; $\mathrm{S}$ 11.49; equiv. wt. 275.1. Calc. for $\mathrm{C}_{14} \mathrm{H}_{16} \mathrm{O}_{4} \mathrm{~S}: \mathrm{C} 59.98 ; \mathrm{H} 5.75$; $\mathrm{S}$ 11.44; equiv. wt. 280.3).

\section{Preparation of unsturated malonic acids}

With the use of sodium hydroxide in excess, the ester hydrolysis yielded the malonic acids which were worked up and purified as described earlier. ${ }^{1}$ In this way the following new compounds were prepared.

2-Ethylthio-2-phenyl-ethen-1,1-dicarboxylic acid ( $\mathrm{V}, \mathrm{R}=\mathrm{C}_{2} \mathrm{H}_{5}-, \mathrm{R}^{\prime}=\mathrm{C}_{6} \mathrm{H}_{5}-$ ). M.p. 199-199.5 (decomp.). (Found: C 57.21; H 4.89; $\mathrm{S}$ 12.68; equiv. wt. 125.8. Calc. for $\mathrm{C}_{12} \mathrm{H}_{12} \mathrm{O}_{4} \mathrm{~S}$ : C 57.13; H 4.79; S 12.71; equiv. wt. 126.15).

2-Benzylthio-2-phenyl-ethen-1,1-dicarboxylic acid ( $\mathrm{V}, \mathrm{R}=\mathrm{C}_{6} \mathrm{H}_{5} \mathrm{CH}_{2}-, \mathrm{R}^{\prime}=\mathrm{C}_{6} \mathrm{H}_{5}-$ ). This acid was found to contain one water of crystallization. M.p. $175-175.5^{\circ}$ (decomp.). (Found: C 62.40; H 4.70; S 9.68; equiv. wt. 166.5. Calc. for $\mathrm{C}_{17} \mathrm{H}_{14} \mathrm{O}_{4} \mathrm{~S} ; \mathrm{H}_{2} \mathrm{O}: \mathrm{C}$ 61.43; $\mathrm{H}$ 4.85; S 9.65; equiv. wt. 166.2).

2-Benzylthio-3-phenyl-1-propen-1,1-dicarboxylic acid (V; $\quad \mathrm{R}=\mathrm{C}_{6} \mathrm{H}_{5} \mathrm{CH}_{2}$-, $\mathrm{R}^{\prime}=\mathrm{C}_{6} \mathrm{H}_{5} \mathrm{CH}_{2}-$ ). M.p. 128-129 (decomp.). (Found: C 65.77; H 4.91; S 9.86; equiv. wt. 164.3. Calc. for $\mathrm{C}_{18} \mathrm{H}_{16} \mathrm{O}_{4} \mathrm{~S}$ : C 65.84; $\mathrm{H} 4.91$; $\mathrm{S} \mathrm{9.76;} \mathrm{equiv.} \mathrm{wt.} \mathrm{164.2).}$

2-Ethylthio-3-methyl-2-buten-1,1-dicarboxylic acid $\left(\mathrm{X}, \mathrm{R}=\mathrm{C}_{2} \mathrm{H}_{5}-\right)$. M.p. 103-104 ${ }^{\circ}$ (decomp.). (Found: $\mathrm{C} 49.78 ; \mathrm{H} \mathrm{6.54;} \mathrm{S} 14.63$; equiv. wt. 109.2. Calc. for $\mathrm{C}_{9} \mathrm{H}_{14} \mathrm{O}_{4} \mathrm{~S}: \mathrm{C} 49.52$; H 6.47; S 14.69; equiv. wt. 109.1).

2-Benzylthio-3-methyl-2-buten-1,1-dicarboxylic acid ( $\mathrm{X}, \mathrm{R}=\mathrm{C}_{6} \mathrm{H}_{5} \mathrm{CH}_{2}-$ ). M.p. 125$126^{\circ}$ (deoomp.). (Found: C 59.98; H 5.76; S 11.38; equiv. wt. 141.1. Calc. for $\mathrm{C}_{14} \mathrm{H}_{16} \mathrm{O}_{4} \mathrm{~S}$ : C 59.98; H 5.75; S 11.44; equiv, wt. 140.2).

\section{Preparation of sulfoxides}

The sulfoxides described below were all synthesized by oxidation of the corresponding sulfides with an equivalent amount of peracetic acid. To the sulfide, dissolved in

Acta Chem. Scand. 22 (1968) No. 5 
acetone or ether, was added the calculated amount of a solution of peracetic acid in acetic acid. The whole was kept in a refrigerator for $48 \mathrm{~h}$ and then the solvent was evaporated yielding the sulfoxide which was recrystallized from a suitable solvent in those cases where this could be performed without decarboxylation of the product.

Ethyl hydrogen 2-ethylsulfinyl-1-propen-1,1-dicarboxylate (VIII, $\mathbf{R}=\mathrm{C}_{2} \mathrm{H}_{5}-$, $\mathbf{R}^{\prime}=\mathbf{C H}_{3}-$ ). The product, consisting of a mixture of the two geometric isomers, was recrystallized from ethyl acetate-petroleum ether. M.p. 99.5-101 ${ }^{\circ}$ (decomp.). (Found: C 46.21; $\mathrm{H}$ 6.03; S 13.78; equiv. wt. 235.6. Calc. for $\mathrm{C}_{9} \mathrm{H}_{14} \mathrm{O}_{5} \mathrm{~S}: \mathrm{C} 46.14 ; \mathrm{H} 6.02 ; \mathrm{S} 13.69$; equiv. wt. 234.3).

Ethyl hydrogen 2-benzylsulfinyl-1-propen-1,1-dicarboxylate (VIII, $\mathrm{R}=\mathrm{C}_{6} \mathrm{H}_{5} \mathrm{CH}_{2}-$, $\mathbf{R}^{\prime}=\mathbf{C H}_{3}-$ ). The mixture of geometric isomers obtained was recrystallized from ethyl acetate. M.p. $113-114^{\circ}$ (decomp.). (Found: C 56.54; H 5.40; S 10.92; Calc. for $\mathrm{C}_{14} \mathrm{H}_{16} \mathrm{O}_{5} \mathrm{~S}$ : C 56.74; H 5.44; S 10.82).

2-Ethylsulfingl-2-phenyl-ethen-1,1-dicarboxylic acid (VI, $\mathrm{R}=\mathrm{C}_{2} \mathrm{H}_{5}-\mathrm{R}^{\prime}=\mathrm{C}_{6} \mathrm{H}_{5}-$ ). Recrystallizations from acetone-petroleum ether yielded a product with m.p. $129-130^{\circ}$ (decomp.). (Found: C 53.79; $\mathrm{H} 4.47 ; \mathrm{S} 11.98$; equiv. wt. 134.9. Calc. for $\mathrm{C}_{12} \mathrm{H}_{12} \mathrm{O}_{5} \mathrm{~S}$ : C 53.72; H 4.51; S 11.95; equiv. wt. 134.1).

2-Benzylsulfinyl-2-phenyl-ethen-1,1-dicarboxylic acid $\quad$ (VI, $\quad \mathbf{R}=\mathrm{C}_{6} \mathrm{H}_{5} \mathrm{CH}_{2}-$, $\mathbf{R}^{\prime}=\mathbf{C}_{6} \mathrm{H}_{5}-$ ). This acid was found to contain one water of crystallization. Recrystallizations from acetone-petroleum ether yielded a product with m.p. 92-93 ${ }^{\circ}$ (decomp.). (Found: C 58.32; $\mathrm{H} 4.61 ; \mathrm{S} \mathrm{9.08;}$ equiv. wt. 174.6. Calc. for $\mathrm{C}_{12} \mathrm{H}_{14} \mathrm{O}_{5} \mathrm{~S}, \mathrm{H}_{2} \mathrm{O}$ : $\mathrm{C} 58.61$; H 4.63; S 9.20; equiv. wt. 174.2).

2-Benzylsulfinyl-3-phenyl-1-propen-1,1-dicarboxylic acid (VI, $\mathrm{R}=\mathrm{C}_{6} \mathrm{H}_{5} \mathrm{CH}_{2}$-, $R^{\prime}=\mathrm{C}_{6} \mathrm{H}_{5} \mathrm{CH}_{2}-$ ). The acid had m.p. $130-140^{\circ}$ (decomp.) after recrystallizations from ethyl acetate-petroleum ether. (Found: C 62.73; H 4.68; S 9.25; equiv. wt. 171.8. Calc. for $\mathrm{C}_{18} \mathrm{H}_{18} \mathrm{O}_{8} \mathrm{~S}$ : $\mathrm{C}$ 62.78; $\mathrm{H}$ 4.68; $\mathrm{S} 9.31$; equiv. wt. 172.2).

2-Ethylsulfingl-3-methyl-2-buten-1,1-dicarboxylic acid ( $\mathrm{XI}, \mathrm{R}=\mathrm{C}_{2} \mathrm{H}_{5}-$ ). Owing to facile decarboxylation, this acid could not be purified by recrystallization. Instead, the substance was finely ground and repeatedly washed with ethyl acetate, in which it was only sparingly soluble. In water it is quite soluble. M.p. $107^{\circ}$ (decomp.). (Found: C 46.58; $\mathrm{H} \mathrm{6.06;} \mathrm{S} \mathrm{13.56;} \mathrm{equiv.} \mathrm{wt.} \mathrm{117.8.} \mathrm{Calc.} \mathrm{for} \mathrm{C}_{9} \mathrm{H}_{14} \mathrm{O}_{5} \mathrm{~S}: \mathrm{C} 46.14 ; \mathrm{H} \mathrm{6.02}$; $\mathrm{S} 13.69$; equiv. wt. 117.1).

2-Ethylsulfinyl-3-methyl-2-buten-1-carboxylic acid (XIII, $\mathrm{R}=\mathrm{C}_{2} \mathrm{H}_{5}-$ ). This acid was readily obtained by warming an acetone solution of the previous compound to $60^{\circ}$ for $1.5 \mathrm{~h}$, after which time the decarboxylation was complete. M.p. $105-106^{\circ}$. (Found: C 50.66; $\mathrm{H} 7.43$; $\mathrm{S} 16.46$; equiv. wt. 190.6. Calc. for $\mathrm{C}_{8} \mathrm{H}_{14} \mathrm{O}_{3} \mathrm{~S}$ : C 50.50; $\mathrm{H} 7.42 ; \mathrm{S} 16.85$; equiv. wt. 190.3 ).

2-Benzylsulfinyl-3-methyl-2-buten-1,1-dicarboxylic acid (XI, $\mathrm{R}=\mathrm{C}_{6} \mathrm{H}_{5} \mathrm{CH}_{2}-$ ). As the corresponding compound with $\mathrm{R}=\mathrm{C}_{2} \mathrm{H}_{5}$, this substance decarboxylated so readily that no recrystallization could be performed and it was therefore treated in the same way. M.p. $107.5-108^{\circ}$ (decomp.). (Found: C 56.99; H 5.49; S 10.90; equiv. wt. 149.9. Calc. for $\mathrm{C}_{14} \mathrm{H}_{16} \mathrm{O}_{5} \mathrm{~S}$ : $\mathrm{C}$ 56.74; $\mathrm{H}$ 5.44; $\mathrm{S} 10.82$; equiv. wt. 148.2).

2-Benzylsulfinyl-3-methyl-2-buten-1-carboxylic acid (XIII, $\mathrm{R}=\mathrm{C}_{6} \mathrm{H}_{5} \mathrm{CH}_{2}-$ ). This acid was obtained by decarboxylation of the previous compound in the same way as just described. M.p. 136-137 . (Found: C 61.66; H 6.30; S 12.64; equiv. wt. 250.1. Calc. for $\mathrm{C}_{13} \mathrm{H}_{16} \mathrm{O}_{3} \mathrm{~S}$ : $\mathrm{C} 61.88 ; \mathrm{H}$ 6.39; $\mathrm{S}$ 12.71; equiv. wt. 252.3).

\section{Preparation of sulfones}

Oxidation of the sulfide-function to sulfone was effected by the use of peracetic acid $50 \%$ in excess of the calculated amount, and in this way the compounds below were synthesized.

2-Ethylsulfonyl-2-phenyl-ethen-1,1-dicarboxylic acid (VII, $\mathrm{R}=\mathrm{C}_{2} \mathrm{H}_{5}-, \mathrm{R}^{\prime}=\mathrm{C}_{6} \mathrm{H}_{5}-$ ). M.p. $148-149^{\circ}$ (decomp.), (from acetone-petroleum ether). (Found: C 50.56; H 4.28; S 11.57; equiv. wt. 142.6. Calc. for $\mathrm{C}_{12} \mathrm{H}_{12} \mathrm{O}_{6} \mathrm{~S}$ : C 50.70; $\mathrm{H} 4.25$; $\mathrm{S} 11.28$; equiv. wt. 142.2). 2-Benzylsulfonyl-2-phenyl-ethen-1,1-dicarboxylic acid (VII, $\mathrm{R}=\mathrm{C}_{6} \mathrm{H}_{5} \mathrm{CH}_{\mathbf{2}}-$, $\mathrm{R}^{\prime}=\mathrm{C}_{6} \mathrm{H}_{5}-$ ). M.p. $180-181^{\circ}$ (decomp.), (from acetone-petroleum ether). (Found: C 58.79; H 4.07; S 9.17; equiv. wt. 174.2. Calc. for $\mathrm{C}_{17} \mathrm{H}_{14} \mathrm{O}_{6} \mathrm{~S}$ : C 58.95; H 4.08; $\mathrm{S} 9.26$; equiv. wt. 173.2). 
2-Benzylsulfonyl-3-phenyl-1-propen-1,1-dicarboxylic acid (VII, $\mathrm{R}=\mathrm{C}_{6} \mathrm{H}_{5} \mathrm{CH}_{2}$-, $\mathrm{R}^{\prime}=\mathrm{C}_{5} \mathrm{H}_{5} \mathrm{CH}_{2}-$ ). M.p. 153-154 ${ }^{\circ}$ (decomp.), (from acetone-benzine). (Found: $\mathrm{C}$ 59.92; $\mathrm{H}$ 4.49; $\mathrm{S}$ 8.92; equiv. wt. 181.2. Calc. for $\mathrm{C}_{18} \mathrm{H}_{16} \mathrm{O}_{8} \mathrm{~S}$ : C 59.99; $\mathrm{H} 4.48$; $\mathrm{S}$ 8.90; equiv. wt. 180.2).

2-Ethylsulfonyl-3-methyl-2-buten-1,1-dicarboxylic acid (XII, $\mathrm{R}=\mathrm{C}_{2} \mathrm{H}_{5}-$ ). M.p. $103-$ $104^{\circ}$ (decomp.), (from ethyl acetate-petroleum ether). (Found: C 49.78; H 6.54; $\mathrm{S}$ 14.63; equiv. wt. 109.2. Calc. for $\mathrm{C}_{9} \mathrm{H}_{14} \mathrm{O}_{6} \mathrm{~S}$ : $\mathrm{C} 49.52 ; \mathrm{H} \mathrm{6.47;} \mathrm{S}$ 14.69; equiv. wt. 109.1).

2-Benzylsulfonyl-3-methyl-2-buten-1,1-dicarboxylic acid (XII, $\mathbf{R}=\mathrm{C}_{8} \mathrm{H}_{5} \mathrm{CH}_{2}-$ ). M.p. $132-133^{\circ}$ (decomp.), (from ethyl acetate-petroleum ether). (Found: $\mathrm{C}_{54.05}$; $\mathrm{H} .17$; $\mathrm{S}$ 10.36; equiv. wt. 125.8. Calc. for $\mathrm{C}_{14} \mathrm{H}_{18} \mathrm{O}_{6} \mathrm{~S}$ : C 53.84; H 5.16; $\mathrm{S}$ 10.27; equiv. wt. 126.1).

\section{Decarboxylation products from $\alpha, \beta-$ unsturated malonic acids}

As already mentioned, decarboxylation of $\mathrm{V}$ in pyridine or DABCO was followed by NMR and passed via the $\beta, \gamma$-unsaturated compound. The reaction was in one case performed on a preparatory scale with isolation of the $\beta, \gamma$-unsaturated mono-acid. Thus, the compound below was prepared.

2-Benzylthio-2-buten-1-carboxylic acid (XV, $\mathrm{R}=\mathrm{C}_{6} \mathrm{H}_{5} \mathrm{CH}_{2}-, \mathrm{R}_{1}=\mathrm{CH}_{3}-$ ). $1 \mathrm{~g}$ of the malonic acid $\mathrm{V}, \mathrm{R}=\mathrm{C}_{6} \mathrm{H}_{5} \mathrm{CH}_{2}-, \mathrm{R}^{\prime}=\mathrm{C}_{2} \mathrm{H}_{5}$, and $0.42 \mathrm{~g}$ of $\mathrm{DABCO}$ was dissolved in a mixture of $10 \mathrm{ml}$ of acetone and $10 \mathrm{ml}$ of water and allowed to stand for $48 \mathrm{~h}$ at $50^{\circ}$. Evaporation of the acetone, dilution with water and drop-wise addition of dilute hydrochloric acid to $\mathrm{pH}=4$, followed by extraction with ether, washing of the etherphase with water, drying and removal of the ether, yielded a crystalline product. An NMR-spectrum showed this to consist of a mixture of the two geometric isomers of $\mathrm{XV}$. It was purified by dissolution in ethyl acetate at room temperature and addition of petroleum ether which caused the formation of crystals after storing in a cold place.

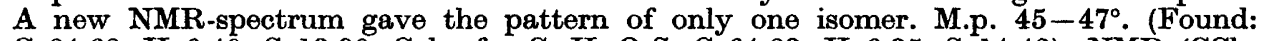
C 64.68; $\mathrm{H} 6.40 ; \mathrm{S} 13.90$. Calc. for $\mathrm{C}_{12} \mathrm{H}_{14} \mathrm{O}_{2} \mathrm{~S}: \mathrm{C} 64.83 ; \mathrm{H} 6.35 ; \mathrm{S}$ 14.42). $\mathrm{NMR}$ ( $\mathrm{CCl}_{4}$, $\delta$-values (ppm) from int. TMS): $7.17\left(\mathrm{C}_{6} \mathrm{H}_{6}-\right), 5.83$ (quartet, $-\mathrm{CH}=, J=7 \mathrm{cps}$ ), 3.78 (benzyl- $\mathrm{CH}_{2}$ ), $3.15\left(\alpha-\mathrm{CH}_{2}\right), 1.67$ (doublet, $\mathrm{CH}_{3}-, J=7 \mathrm{cps}$ ). The peaks at 5.83, 3.15, and 1.67 showed additional fine structure due to coupling via the double bond.

The NMR-spectra were recorded with a Varian A-60 spectrometer. The chemical shifts were measured from tetramethylsilane which was used as an internal reference. Methanol- $d_{4}$ and acetone- $d_{6}$ were used as solvents for the free acids and the esters were studied in carbon tetrachloride or deuteriochloroform. Spectra of acids in methanol-d. were recorded immediately in order to avoid any eventually occurring esterification.

The melting points given for the the malonic acids are of course of limited value because all these compounds underwent decarboxylation. Because of a varying degree of reproducibility of these decomposition temperatures, however, they may be of interest and are therefore given in connection with the other data. The determination of the melting points was carried out with the use of capillary tubes, an electrically heated apparatus and a rate of heating of approximately 1 degree $/ \mathrm{min}$.

Acknowledgement. We are indebted to Professor A. Fredga for his stimulating interest in this work and for the facilities placed at our disposal. A grant from the Swedish Na. tural Science Research Council to one of us (S.A.) is gratefully acknowledged.

\section{REFERENCES}

1. Allenmark, S. and Bohman, O. Acta Chem. Scand. 20 (1966) 1409.

2. Allenmark, S. Arkiv Kemi 26 (1966) 37.

3. Campaigne, E. and Leal, J. R. J. Am. Chem. Soc. 76 (1954) 1272.

4. Hauptmann, H. and Giora, A. C. Tetrahedron Letters 1960 No. 11, 1.

5. Szmant, H. H. In Organic Sulfur Compounds, Pergamon, Oxford 1961, Vol I, p. 157.

6. Amstutz, E. M., Hunsberger, I. M. and Chessick, J. J. J. Am. Chem. Soc. 73 (1951) 1220. 
7. Gould, E. S. Mechanism and Structure in Organic Chemistry, Holt, Rinehart and Winston, New York 1964, p. 346.

8. Abell, P. I. and Tien, R. J. Org. Chem. 30 (1965) 4212.

9. Fraenkel, G.. Belford, R. L. and Yankwich, R. E. J. Am. Chem. Soc. 76 (1954) 15.

10. Hogeveen, H.. Maccagnani, G. and Taddei, F. Rec. Trav. Chim. 83 (1964) 937.

11. Allenmark, S. and Hagberg, C.-E. Arkiv Kemi 26 (1966) 1 and unpublished results.

12. Arbouzov, B. A. and Samitov, Y. Y. Tetrahedron Letters 1963473.

13. Pritchard, J. G. and Lauterbur, P. C. J. Am. Chem. Soc. 83 (1961) 2105.

14. Buck, K. W., Foster, A. B., Perry, A. R. and Webber, J. M. Chem. Commun. 1965 433.

15. Buck, K. W., Foster, A. B., Pardoe, W. D., Quadir, M. H. and Webber, J. M. Chem. Commun. 1966759.

16. Hogeveen, H., Maccagnani, G., Montanari, F. and Taddei, F. J. Chem. Soc. 1964 682 .

17. Foster, A. B., Duxbury, J. M., Inch, T. D. and Webber, J. M. Chem. Commun. 1967 881.

18. Rauk, A., Buncel, E., Moir, R. Y. and Wolfe, S. J. Am. Chem. Soc. 87 (1965) 5498.

19. Wolfe, S. and Rauk, A. Chem. Commun. 1966778.

20. Mislow, K., Glass, M. A. W., Hopps, H. B., Simon, E. and Wahl, G. H. J. Am. Chem. Soc. 86 (1964) 1718 .

21. Moriarty, R. M. J. Org. Chem. 30 (1965) 600.

22. Corey, E. J. J. Am. Chem. Soc. 74 (1952) 5897.

23. Corey, E. J. J. Am. Chem. Soc. 75 (1953) 1163.

24. Corey, E. J. and Fraenkel, G.J.Am. Chem. Soc. 75 (1953) 1168.

25. Lund, H. Ber. 67 (1934) 937.

26. Tarbell, D. S. and Price, J. A. J. Org. Chem. 22 (1957) 245.

27. von Auwers, K. and Auffenberg, E. Ber. 50 (1917) 929.

28. Markow, P., Ivanoff, C. and Arnaudov, M. Chem. Ber. 97 (1964) 2987.

29. Borsche, W. and Wannagat, U. Chem. Ber. 85 (1952) 193.

30. Brown, H. C. J. Am. Chem. Soc. 60 (1938) 1326.

31. Brändström, A. Arkiv Kemi 6 (1954) 201.

32. Libermann, D. and Hengl, L. Bull. Soc. Chim. France 1951974.

33. von Auwers, K. and Jacobsen, H. Ann. 426 (1922) 174.

Received December 9, 1967. 